OPEN ACCESS

Edited by:

Juan Jose Munoz-Perez,

University of Cádiz, Spain

Reviewed by:

Fialho Nehama,

Eduardo Mondlane University,

Mozambique

Wenping Gong,

Sun Yat-sen University, China

*Correspondence:

Alexander Osadchiev

osadchiev@ocean.ru

Specialty section:

This article was submitted to

Coastal Ocean Processes,

a section of the journal

Frontiers in Marine Science

Received: 05 November 2021

Accepted: 29 November 2021

Published: 16 December 2021

Citation:

Osadchiev A, Sedakov R and Barymova A (2021) Response of a Small River Plume on Wind Forcing. Front. Mar. Sci. 8:809566 doi: 10.3389/fmars.2021.809566

\section{Response of a Small River Plume on Wind Forcing}

\author{
Alexander Osadchiev ${ }^{1,2 *}$, Roman Sedakov ${ }^{1}$ and Alexandra Barymova ${ }^{3}$ \\ ${ }^{1}$ Shirshov Institute of Oceanology, Russian Academy of Sciences, Moscow, Russia, ${ }^{2}$ Moscow Institute of Physics \\ and Technology, Dolgoprudny, Russia, ${ }^{3}$ Marine Research Center at Lomonosov Moscow State University, Moscow, Russia
}

Wind forcing is the main driver of river plume dynamics. Direction and magnitude of wind determine position, shape, and size of a river plume. The response of river plumes on wind forcing was simulated in many numerical modeling studies; however, in situ measurements of this process are still very scarce. In this study, we report the first direct measurements of frontal movement of a small river plume under variable wind forcing conditions. Using quadcopters, we performed nearly continuous daytime aerial observations of the Bzyb river plume located in the non-tidal Black Sea. The aerial remote sensing was accompanied by synchronous in situ measurements of wind forcing. We assessed spreading patterns of the plume and evaluated movement velocity of its outer border with unprecedentedly high spatial ( $\sim 10 \mathrm{~m})$ and temporal ( $\sim 1 \mathrm{~min})$ resolution, which was not available in previous studies based on in situ measurements and satellite observations. Based on the collected data, we evaluated the time of response of plume spreading dynamics on changes in wind forcing conditions. The advection velocity of the outer plume border shows linear relation to wind speed with very small response time (10-20 min). The reversal between upstream/downstream plume spreading occurs during several hours under moderate wind forcing conditions. These reversals involve only near-field part of the plume, which cause detachment of the far-field part of the plume. The obtained results are crucial for understanding and simulating spreading dynamics of small river plumes worldwide.

Keywords: small river plume, wind forcing, coastal circulation, surface currents, aerial remote sensing, Black Sea

\section{INTRODUCTION}

Wind forcing and river discharge rate are two major factors that govern spreading of river plumes. Generally, spatial scales of a river plume are determined by river discharge rate, i.e., volume of fresh water that forms the plume. River discharge generally has large seasonal variability, which regulate seasonal variability of a river plume (Thomas and Weatherbee, 2006; Lihan et al., 2008; Saldias et al., 2012). Wind forcing generally governs synoptic variability of stratified river plumes (Liu et al., 2009; Horner-Devine et al., 2015). Temporal scales of discharge-driven and wind-driven variability decrease with for smaller spatial scales of river plumes. In particular, discharge-driven variability of small river plumes can be synoptic (Yankovsky et al., 2001; O'Callaghan et al., 2010; Yuan et al., 2018) and diurnal (Osadchiev and Korshenko, 2017; Cole et al., 2020), while wind forcing determine diurnal and even hourly variability of small river plumes (Pinones et al., 2005; Qu and Hetland, 2019; Osadchiev et al., 2020a, 2021a). 
Wind impulse limitedly penetrates below the bottom boundary between a river plume and subjacent saline sea (Xia et al., 2011; Osadchiev and Zavialov, 2020). As a result, wind energy is concentrated in relatively shallow surface layer that causes more intense wind-driven advection of a river plume as compared to less stratified ambient sea. Similarly, ambient sea circulation affects river plume dynamics much less than wind forcing due to density gradient between a river plume and subjacent saline sea, which hinders upward flux of impulse (Osadchiev and Zavialov, 2013; Zu et al., 2014). Ambient currents can be the dominant driver of plume dispersal, albeit only for diluted outer parts of large plumes (Nikiema et al., 2007; Osadchiev, 2017; Osadchiev et al., 2020b; Nehama and Reason, 2021), while spreading of stratified river plumes is governed by wind forcing. As a result, wind-driven dynamics of a river plume is significantly different from that of the ambient saline sea. This feature strongly affects land-ocean exchange processes. Under strong wind forcing conditions, river-borne suspended and dissolved matter can be effectively transported within river plumes far off its sources in river estuaries as compared to suspended and dissolved material contained in saline sea water (Perianez, 2005; Shi and Wang, 2010; Osadchiev and Korshenko, 2017; Osadchiev et al., 2019; Korshenko et al., 2020).

Many previous works addressed wind-driven spreading of river plumes (e.g., Fong and Geyer, 2001; Berdeal et al., 2002; Hallock and Marmorino, 2002; Houghton et al., 2004; Lentz, 2004; Whitney and Garvine, 2005; Lentz and Largier, 2006; Choi and Wilkin, 2007; Williams et al., 2010; Rao et al., 2011; Lentz and Fewings, 2012; Moffat and Lentz, 2012; Zhao et al., 2018; Osadchiev and Sedakov, 2019; Osadchiev et al., 2020c). However, the majority of these works were based on numerical modeling of river plumes under different wind forcing conditions. Studies of this process based on in situ observations are still very scarce due to complexity of simultaneous thermohaline and velocity measurements at various plume regions with highly variable properties, positions, and circulation patterns. Nevertheless, in situ measurements of different plume characteristics (vertical structure, location of outer front, spreading direction, inner circulation, etc.), which change in response to changes in wind forcing conditions, are crucial for general understanding of spreading and mixing of river plumes. These measurements are essential for validation of numerical models and correct simulation of river plumes worldwide.

Quadcopters, which recently started to be applied in field surveys, provide unprecedented ability to continuously observe river plumes (Osadchiev et al., 2020a, 2021a,b). Aerial imagery and video records obtained by quadcopters can be used to reconstruct spatial and dynamical characteristics of river plumes with high spatial and temporal resolution. As a result, simultaneous measurements of wind forcing and continuous observations of a small river plume from a quadcopter provide ability for qualitative and quantitative assessment of response of a river plume on wind forcing. It is especially efficient for small river plumes, which can be almost completely observed from a single quadcopter from the altitudes of 100-500 m.

In this study, we report field measurements, which were performed in April 2021 at the Bzyb river plume located in the eastern part of the Black Sea (Osadchiev et al., 2020a, 2021a,b). Observations of the plume from a quadcopter at daytime during 3 days with variable wind forcing conditions were accompanied by wind measurements on-site, as well as thermohaline and current velocity measurements at the sea. Based on the collected data, we evaluated the time of response of plume spreading dynamics on changes in wind forcing conditions. In addition, we evaluated the dependence between spreading direction of the plume and movement velocity of its outer border on direction and magnitude of wind speed.

\section{DATA AND METHODS}

Field measurements analyzed in this study were performed on 14-17 April 2021 at the area adjacent to the Bzyb river mouth in the eastern part of the Black Sea (Figure 1). Aerial observations of the Bzyb plume by DJI Mavik 2 Zoom quadcopters equipped with a $12 \mathrm{MP} / 4 \mathrm{~K}$ video cameras were performed during daytime (from 8 am to $7 \mathrm{pm}$ ). Quadcopters were lifted to the altitude of $500 \mathrm{~m}$ every 30-60 min from the spot located at the seashore $1 \mathrm{~km}$ northward from the river mouth (indicated by the red circle in Figure 1C) that provided opportunity to fix the observation point. Images of the plume at the angle $\sim 60^{\circ}$ were taken every $3 \mathrm{~s}$, quadcopter flights lasted 15-20 min. Usage of two quadcopters and multiple batteries provided ability to alternate their flights and to download data from one quadcopter during the flight of the other quadcopter. The resulting temporal coverage of the field survey period by images of the plume is shown by gray and black bands in Figure 2.

Wind forcing was measured by Gill GMX200 wind speed and direction sensor located in the same place as the quadcopter spot (indicated by the red circle in Figure 1). The sensor was mounted to a pole and performed measurements at the altitude of $8 \mathrm{~m}$ with 1-min intervals. Satellite data used in this study include Landsat 8 optical image of the study area acquired on 14 April 2021 at 11:01 and Sentinel-2 optical image acquired on 15 April 2021 at 11:28 (indicated by black arrows in Figure 2). Note that these satellite images were acquired synchronously with aerial remote sensing. Therefore satellite data was used only to indicate the direction of plume movement, and no scientific analysis was made based on satellite images. Thermohaline and velocity measurements at the sea area adjacent to the Bzyb mouth were performed by CastAway CTD instrument and Nortek Aquadopp ADCP profiler.

The remote sensing data processing included georeferencing of the aerial imagery by direct projection into an earth-based Cartesian coordinate system using GPS and altimetry data from the quadcopter. The obtained projection was validated and corrected according to location of ground control points with well-known coordinates registered at the imagery, namely, river mouth capes, lakes near the river mouth, buildings. Georectification of the UAV imagery was performed based on the ground control points. The exact coordinates of the river mouth and sea shoreline at the georectified imagery were validated against the Sentiunel-2 satellite image (with $10 \mathrm{~m}$ spatial resolution) taken during the period of field work. This is an important issue due to regular morphologic changes induced by 


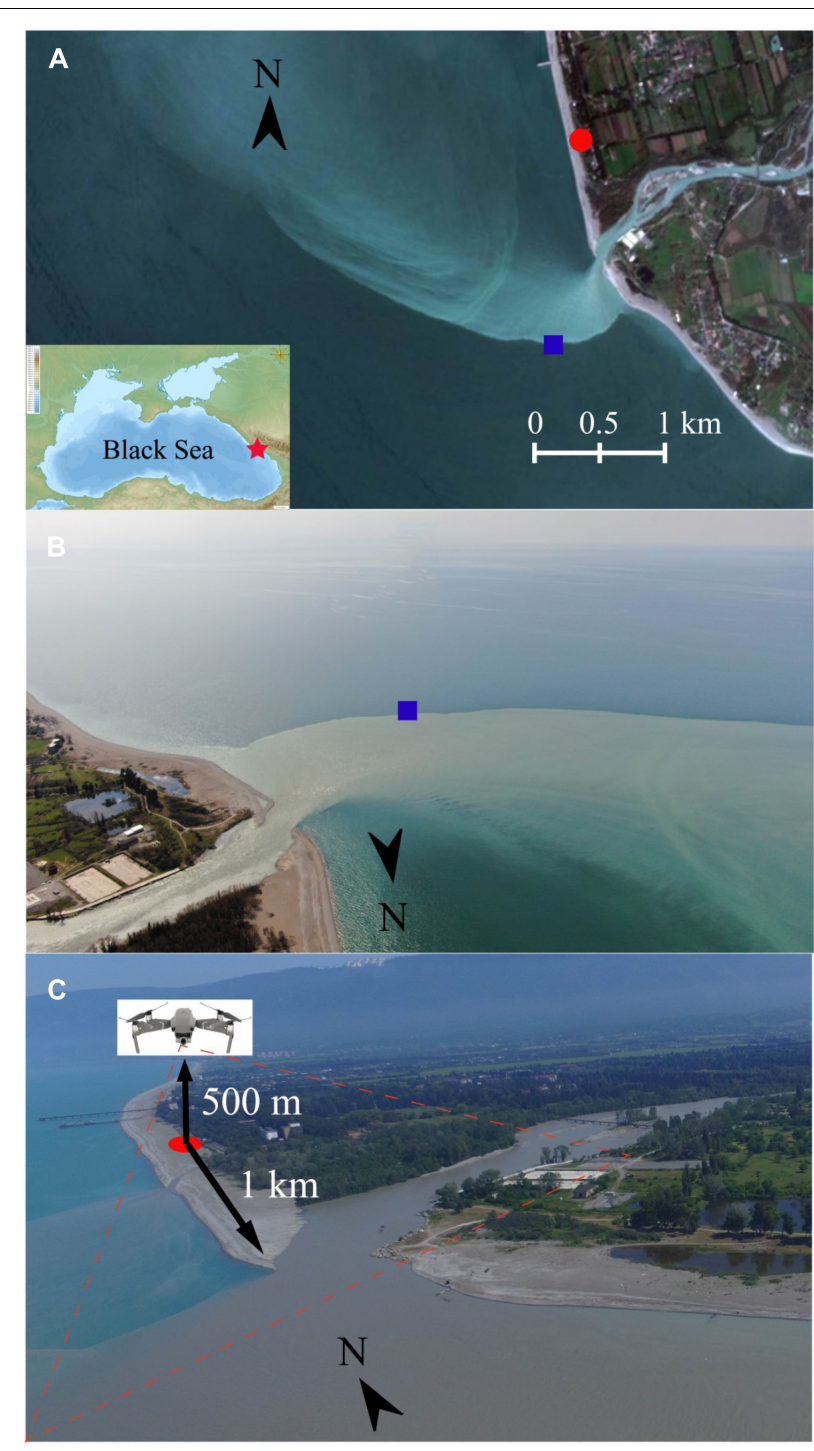

FIGURE 1 | Satellite (A) and aerial (B) images of the Bzyb plume acquired on 15 April 2021 at 11:20 (B) and 11:28 (A), i.e., almost simultaneously. Scheme of quadcopter observations at the study area (C). The red circles in the panels $(\mathbf{A}, \mathbf{C})$ indicate the place where the quadcopter spot and the meteorological station were located. The blue squares in the panels $(\mathbf{A}, \mathbf{B})$ indicate the place of ADCP measurements at the plume border. The red star at the inset in panel (A) indicates the location of the study area at the eastern part of the Black Sea. The dashed red triangle in the panel (C) indicates the quadcopter observation angle. Note that the aerial image shown in the panel (C) was taken during the other day that the almost simultaneous images shown in the panels $(\mathbf{A}, \mathbf{B})$.

river channel processes, which are very intense in the study area. The vertical and horizontal accuracy of quadcopter positioning are 0.1 and $0.3 \mathrm{~m}$, respectively. Once the remote sensing was performed from the altitude of $500 \mathrm{~m}$ on a distance of $1 \mathrm{~km}$ from the study area, the accuracy of direct projection is $<1 \mathrm{~m}$.

The choice of the point and angle of aerial remote sensing is crucial for this study. The observation area should cover the area of interest in the coastal sea. On the other hand, in order to obtain accurate georeferencing using multiple onshore ground control points, the observed area should partly cover the coast. The increase of altitude of remote sensing widens the observation area. However, this altitude is limited, first, by the camera resolution and, second, by regulations of national aviation administrations and quadcopter manufacturers, which seems to be more important. In particular, the $D J I$ quadcopters used in our study have a hard-coded altitude limitation equal to $500 \mathrm{~m}$, which was the exact operation altimetry in our study. The increase of the observation angle also widens the observation area, albeit only to a certain extent due to the projective distortion of the imagery.

In case of this study, the quadcopters observed the river mouth, the near-field part of the plume, and partly the far-filed plume. A small river plume generally has two types of outer border, namely, diffuse and sharp fronts (Osadchiev and Sedakov, 2019). A diffuse frontal zone is formed from the side of plume movement direction, i.e., in front of a spreading plume. A sharp frontal zone is formed from the opposite side, i.e., behind of a spreading plume. A sharp front is narrow (tens of centimeters for the Bzyb plume) and is distinctly visible in aerial imagery. As a result, motion of this part of the plume boundary could be accurately detected by aerial remote sensing, which is not the case of the diffuse front.

The main limitations of the described methodology, despite those related to altitude and observation area and described above, consist in turbidity of river water and weather conditions. The plume is visible at the aerial images due to its high turbidity, as compared to ambient seawater. However, low turbidity of river water limits detection of a river plume. Usage of quadcopters is hindered during rain and strong winds, which is a serious limitation for studying river plumes, because it inhibits observations of response of river plumes to strong winds and short-term rain-induced flooding events. Finally, aerial observations of river plumes are inhibited during dusk and under overcast sky conditions.

\section{RESULTS}

The field survey was carried during the spring freshet at the Bzyb River. Freshwater discharge rate reconstructed from direct velocity and depth measurements in the river mouth was $\sim 200 \mathrm{~m}^{3} / \mathrm{s}$. According to CTD measurements and satellite observations, the Bzyb plume occupied area $\sim 10 \mathrm{~km}^{2}$, while the depth of the plume was $2-3 \mathrm{~m}$. At the bottom boundary of the plume salinity abruptly increased by 2-3 units at the vertical distance of $<1 \mathrm{~m}$. Large salinity gradient was formed at the distinct outer border of the Bzyb plume near the river mouth, salinity in the surface layer increased from 4.5 in the plume to 15 in the ambient sea at the horizontal distance of $6 \mathrm{~m}$. These large vertical and horizontal salinity gradients are typical for small mountainous river plumes formed in the northeastern part of the Black Sea (Osadchiev, 2018; Osadchiev et al., 2020a, 2021a).

Tidal circulation in the Black Sea is very low, tidal amplitudes in the study area are less than $6 \mathrm{~cm}$ (Medvedev et al., 2016; Medvedev, 2018). Ambient sea circulation in the study area also was low during the field survey. ADCP measurements performed 


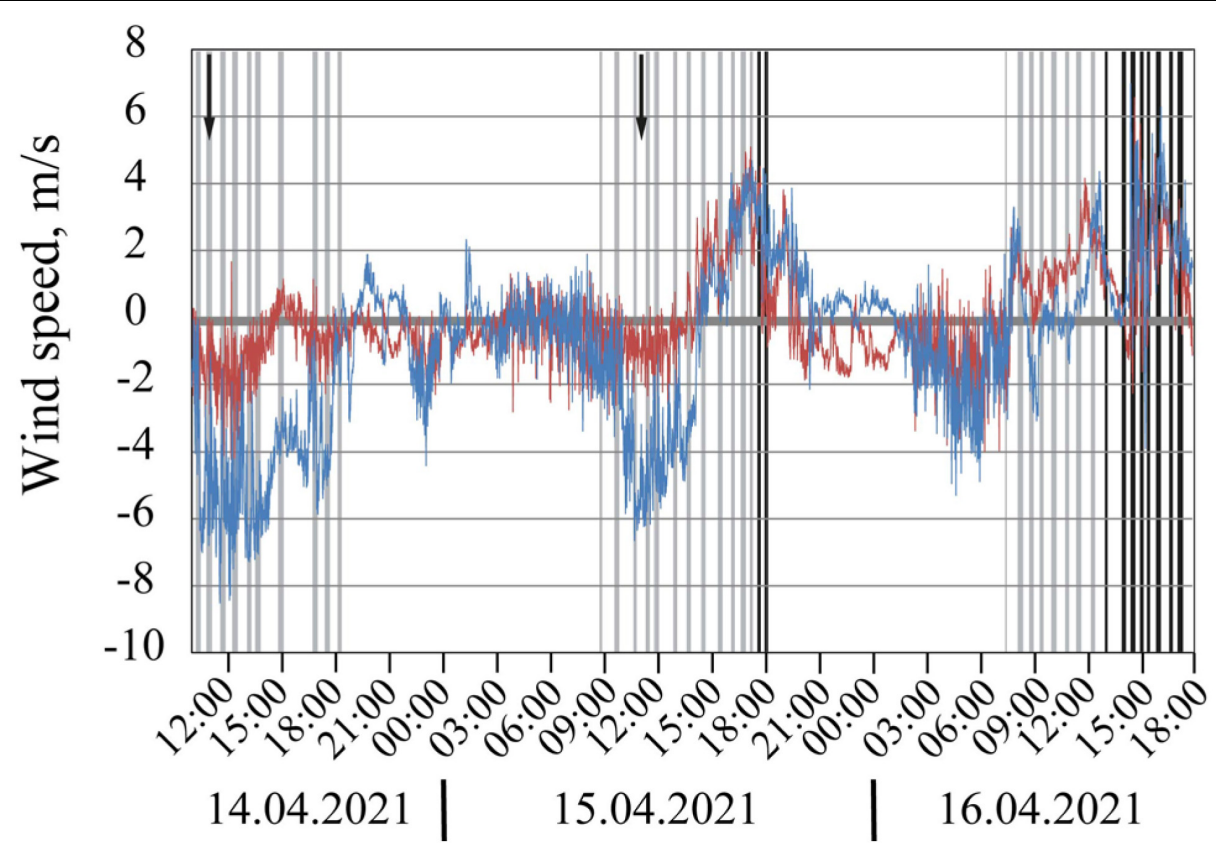

FIGURE 2 | Eastward (blue) and northward (red) components of wind speed on 14-16 August 2021 at the study area. Gray and black bands indicate periods of aerial observations of the Bzyb plume, gray band mark northward spreading of the plume, black bands mark southward spreading of the plume. Two black arrows indicate times of two satellite images of the study area acquired during the period of field survey.

$500 \mathrm{~m}$ seaward from the Bzyb mouth showed that current velocity below the plume, i.e., at the depths $>4 \mathrm{~m}$, did not exceed $20 \mathrm{~cm} / \mathrm{s}$. As a result, the dynamics of the Bzyb plume during the considered period was governed by variability of wind forcing. Wind forcing during the field survey was moderate, wind speed was $<5 \mathrm{~m} / \mathrm{s}$ during $90 \%$ of the study period, average wind speed was $2.5 \mathrm{~m} / \mathrm{s}$ (Figure 2).

The main advantage of the performed continuous aerial observations of the Bzyb plume (as compared to in situ measurements and satellite observations) consists in its potential to reveal the response of the plume dynamics on variability of wind forcing on small temporal scales, i.e., minutes and hours. The main observed feature of the plume dynamics on the hourly temporal scale consists in change of its spreading direction. The Bzyb plume was spreading northward during the majority of the observation periods (marked by gray bands in Figure 2). However, northward spreading of the plume twice switched to southward spreading at $\sim 18: 00$ on 15 April and at $\sim 15: 00$ on 16 April (marked by black bands in Figure 2). In both cases this process, was in detail registered by aerial observations (Figure 3 ). Northward spreading of the plume was distinctly associated with negative zonal component of wind speed, which dominated on 14 April $(-2$ to $-6 \mathrm{~m} / \mathrm{s})$, at the first half of 15 April $(-2$ to $-6 \mathrm{~m} / \mathrm{s})$, and at the first half of 16 April $(-2$ to $-1 \mathrm{~m} / \mathrm{s})$. Once the zonal component of wind speed changed to positive at $\sim 15: 00$ on 15 April and at $\sim 11: 00$ on 16 April, it took 3$4 \mathrm{~h}$ for the Bzyb plume to change its spreading direction from northward to southward. In both cases, the observed quick reversal was induced by moderate wind forcing $(1-4 \mathrm{~m} / \mathrm{s})$. The observed dependence of northward-southward spreading of the plume on the zonal wind component is caused by large values of the angle between wind direction and Ekman transport (up to $60-80^{\circ}$ ) within small and stratified river plumes, which was described in Osadchiev and Sedakov (2019). In this case, the positive/negative cross-shore wind component $(u)$ corresponds to upwelling/downwelling favorable conditions.

In order to obtain quantitative assessments of the relation between wind forcing and plume spreading dynamics, we reprojected the aerial images (Figures $\mathbf{3 A}, \mathbf{B}$ ) to an earthbased Cartesian coordinate system (Figures 3C,D). At the georeferenced images we reconstructed the location of the distinct outer border of the plume, which can be located southward/northward from the river mouth in case of northward/southward spreading direction of the plume. Then we calculated motion direction and velocity of the plume outer border for all pairs of sequential images. The obtained velocities showed good agreement with synchronous ADCP measurements, which were performed near the plume border on 14 April (blue squares in Figure 1). Based on this data, we analyzed the response of the plume dynamics on variability of wind forcing on sub-hourly temporal scale (Figure 4).

On 14 April, the plume was spreading northward, its outer border steadily moved northward toward the river mouth under moderate offshore wind forcing $(4-6 \mathrm{~m} / \mathrm{s})$. Once the wind switched to light onshore $(0-2 \mathrm{~m} / \mathrm{s})$, the movement direction of the outer plume border changed to southward. On 15 April, the increase of offshore wind from 1-2 to 4-6 m/s also induced northward motion of the plume border. The following relaxation of the offshore wind to $3-4 \mathrm{~m} / \mathrm{s}$ and then its change to light onshore wind (0-2 m/s) induced southward motion of the 


\section{A \\ 15 April 2021}

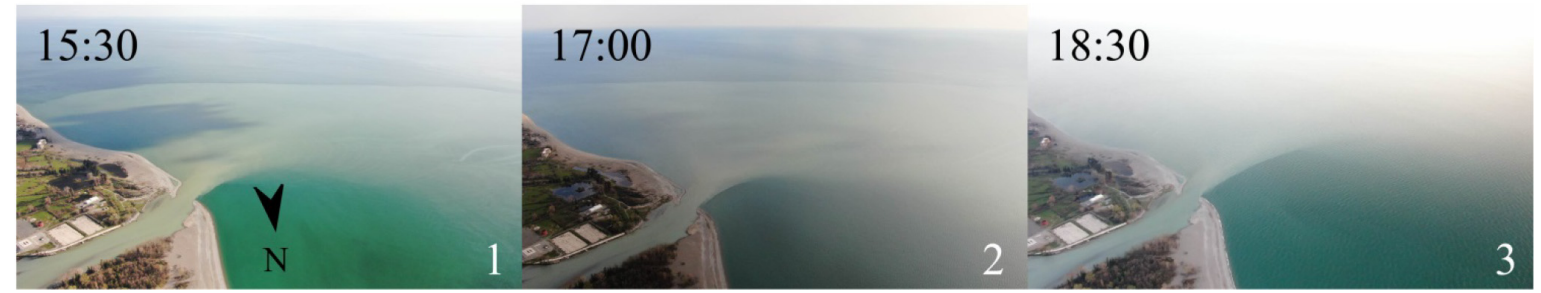

B

16 April 2021
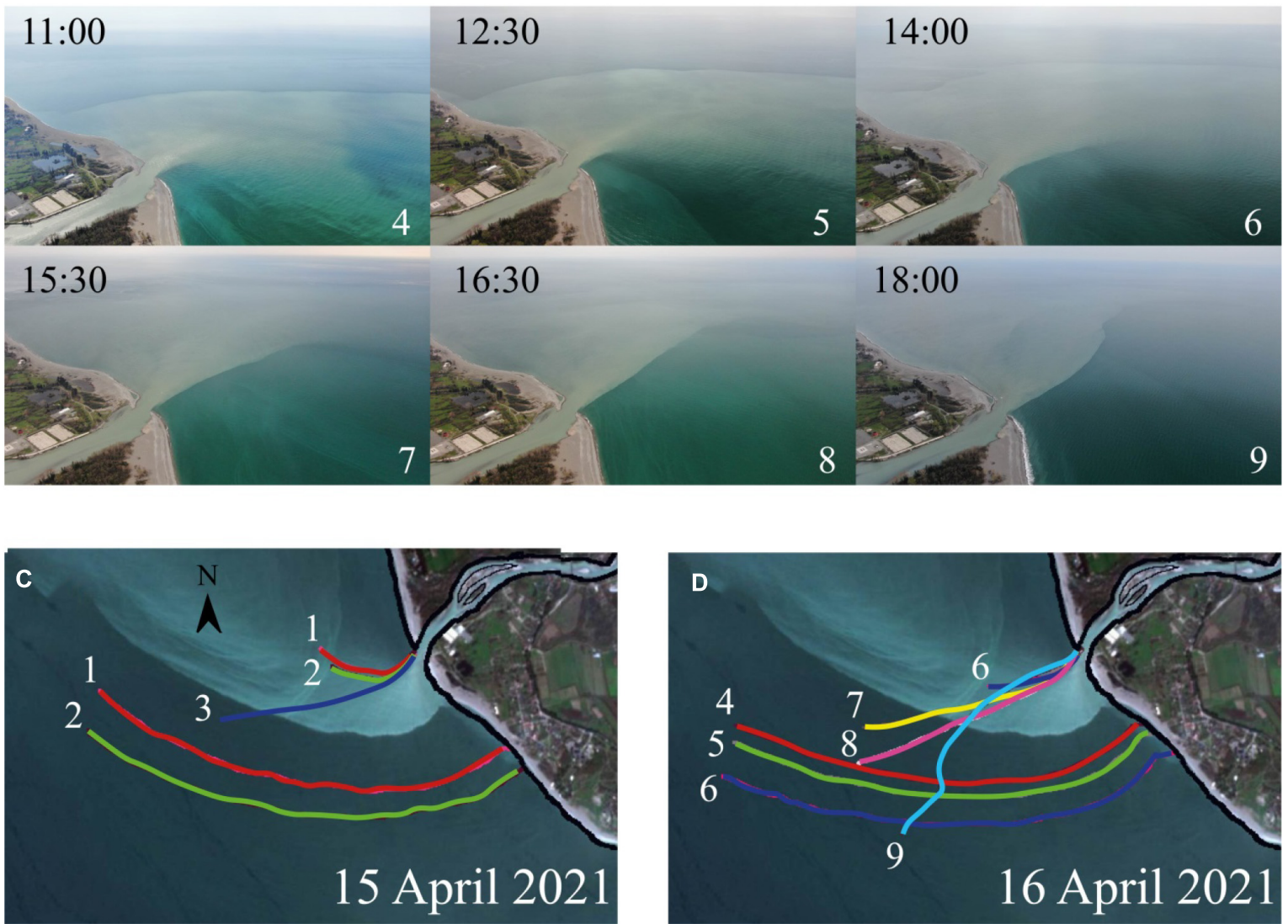

FIGURE 3 | Change of spreading direction of the Bzyb plume registered by aerial observations (A,B) and at the respective georeferenced images (C,D) on 15 April 2021 (A,C) and 16 April 2021 (B,D). Colored lines and numbers in panels (C,D) represent the subsequent locations of the Bzyb plume border at time periods shown in panels (A,B), respectively. The background image in panels (C,D) is the Sentinel-2 satellite image of the study area acquired on 15 April 2021 at 11:28.

plume border, which in several hours resulted in change of the plume spreading direction (Figures 3A,C). On 16 April, the plume border varied only slightly when wind forcing conditions changed between offshore and onshore $(<2 \mathrm{~m} / \mathrm{s})$, then light onshore wind $(2-4 \mathrm{~m} / \mathrm{s})$ caused southward motion and reversal of the plume (Figures 3B,D). During all 3 days, the observed response time of the motion of the outer plume border on changes in wind conditions were $10-20 \mathrm{~min}$.

The reconstructed movement velocity of the Bzyb plume outer border during 3 days of the field survey provided the linear dependence $s=u / 20$ between zonal wind speed $u$ and advection velocity of the distinct southern border of the plume $s$ (Figure 4). The Pearson correlation coefficient for this relation is equal to 0.85 . The obtained relation demonstrates that even low wind forcing equal to $2-4 \mathrm{~m} / \mathrm{s}$ results in relatively large movement velocity of the plume border equal to $0.1-0.2 \mathrm{~m} / \mathrm{s}$. Once the displacement of the plume border equal to $\sim 1 \mathrm{~km}$ results in reversal of northward/southward spreading direction of the plume, wind forcing of 2-4 m/s reverses the plume during 1.5$3 \mathrm{~h}$. This temporal scale of the Bzyb plume reversal is consistent with aerial observations of this process. If the wind speed exceeds $5.5 \mathrm{~m} / \mathrm{s}$, the reversal occurs during less than an hour. 


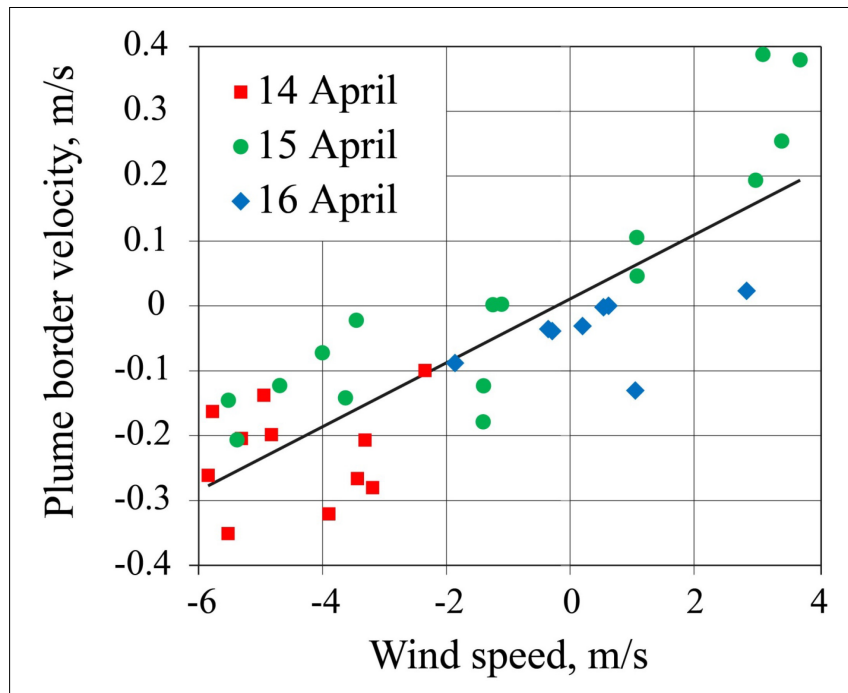

FIGURE 4 | Dependence between zonal wind speed and movement velocity of the plume outer border during the field survey. The black line indicates the linear trend.

\section{DISCUSSION AND CONCLUSION}

This work is focused on evaluation of response of a small river plume on variable wind forcing. For this purpose, we studied the Bzyb river plume located in the eastern part of the Black Sea. The field survey was performed during weak external forcing conditions, i.e., freshwater discharge $\sim 200 \mathrm{~m}^{3} / \mathrm{s}$, almost no tide, and light ambient coastal circulation. It provided opportunity to assess the effects of light and moderate wind forcing on river plume spreading using field observations.

We performed aerial remote sensing of the Bzyb river plume from the fixed point at the altitude of $500 \mathrm{~m}$ using quadcopters during the field survey on 14-16 April 2021. These observations provided almost continuous detection of position of the Bzyb plume during daytime of these 3 days with variable wind forcing conditions. The remote sensing of the plume was accompanied by wind measurements at the study area with temporal resolution of $1 \mathrm{~min}$. Georeferencing of the obtained aerial imagery provides ability to qualitatively assess spreading patterns of the plume and evaluate movement velocity of its outer border. This methodology is relatively simple and straightforward, however, it provides very high spatial $(\sim 10 \mathrm{~m})$ and temporal $(\sim 1 \mathrm{~min})$ resolution of plume spreading variability, which was not available in previous studies based on in situ measurements and satellite observations of river plumes. Numerous previous studies used numerical modeling to quantify the response of a river plume on variable wind forcing; however, we are not aware of any study based on direct observations and measurements of this process at such small spatial and temporal scales. Nevertheless, precise description of this process is crucial for understanding and simulating spreading and mixing of river plumes worldwide.

During the study period, the zonal wind component determined position of the plume. The plume was spreading southward/northward along the shore under onshore/offshore wind. Changes in the wind direction resulted in reversal of spreading direction of the plume, which was observed several times during the field survey. The time differences between the observed reversals of motion direction of the plume border and the preceding changes in wind forcing were equal to 10 $20 \mathrm{~min}$. This very small time scale of response of the Bzyb plume spreading dynamics on wind forcing variability is the first main finding of this study.

The quick response of the Bzyb plume on wind forcing results in stable linear relation between advection velocity of the plume border and magnitude of zonal wind speed, which is the second main finding of this study. According to the obtained relation, velocity of the plume border is equal to zonal wind speed divided by 20; this relation is universal for both onshore and offshore winds. As a result, a shift between onshore and offshore wind even under low wind speed conditions $(<5 \mathrm{~m} / \mathrm{s})$ results in total change of the plume spreading direction and, therefore, the plume position during less than several hours. Aerial imagery demonstrates that these plume reversals were limited to the relatively small near-field area of the plume and did not involve the majority of the far-field part of the plume. As a result, the wind-induced quick plume reversal induces formation of a new plume adjacent to the river mouth rather than changes position of the existing plume. In particular, the observed area of the Bzyb plume shortly after the northward-southward reversals reduced from $\sim 10$ to $\sim 2.5 \mathrm{~km}^{2}$. As a result, variability of wind direction is an important mechanism of detachment of the far-field part of the plume from its freshwater source, which results in its downstream advection of the old plume and presumably intensifies its mixing (Yankovsky et al., 2001; Mazzini and Chant, 2016; Yuan et al., 2018), which is the third main finding of this study.

The spreading dynamics of the small Bzyb plume continuously observed during 3 days clearly demonstrated the absence of a recirculating bulge near the river mouth even under low wind forcing conditions. The anticyclonic circulation within a plume under low external forcing (also called as the mid-field plume) is a common feature of classical idealized numerical models (Yankovsky and Chapman, 1997; Fong and Geyer, 2002; Horner-Devine et al., 2006; Choi and Wilkin, 2007), however, it is very rarely registered by in situ measurements and satellite observations (Horner-Devine, 2009; Osadchiev and Sedakov, 2019). Also, quick freshwater accumulation in the near-field part of the plume under low external forcing (also called as the plume ballooning), which was predicted by numerical and laboratory modeling (Nof and Pichevin, 2001; Fong and Geyer, 2002; Horner-Devine et al., 2006), was not observed at the Bzyb plume. The offset between the trend line and the point $(0 ; 0)$ is small, almost equal to zero (Figure 4). It shows that the river plume has stable or almost stable position in case of very low wind forcing. However, we want to highlight that the location of the trend line could change to a certain extent in case of longer measurements and accumulation of more "wind speed-plume border velocity" points. As a result, the offset of the trend line from point $(0 ; 0)$ also could change in case of longer measurements. However, we presume that this offset will remain rather small, i.e., $<0.1 \mathrm{~m} / \mathrm{s}$ for plume border velocity for zero wind forcing. 
The response of the small Bzyb plume to upwelling/ downwelling winds was significantly different to that described in conceptual models for large plumes based on analytical equations and numerical simulations (Fong and Geyer, 2001; Lentz, 2004; Lentz and Largier, 2006; Lentz and Fewings, 2012; Moffat and Lentz, 2012). The near-field part of the Bzyb plume responses very quickly to the changes in upwelling/downwelling winds because of re-shaping the new near-field plume with completely different spreading direction. As a result, the outer part of the plume (old plume) becomes detached from the near-field plume (new plume) due to their significantly different movement velocities. Aerial observations demonstrated that shortly after the plume reversal the detached outer part of the plume covers much wider area than the newly formed plume attached to the river mouth (Figure 5A). CTD measurements performed at the study area showed dramatic difference in vertical stratification at these water masses that determines difference in response of the new and old plumes to wind forcing (Figure 5B). In particular, the new plume spreading above the old plume forms a threelayered stratification (green vertical profile in Figure 5B). Similar vertical structure of the old and new plumes was previously observed at the small Kodor plume, which is located nearby the

A

16 April 2021

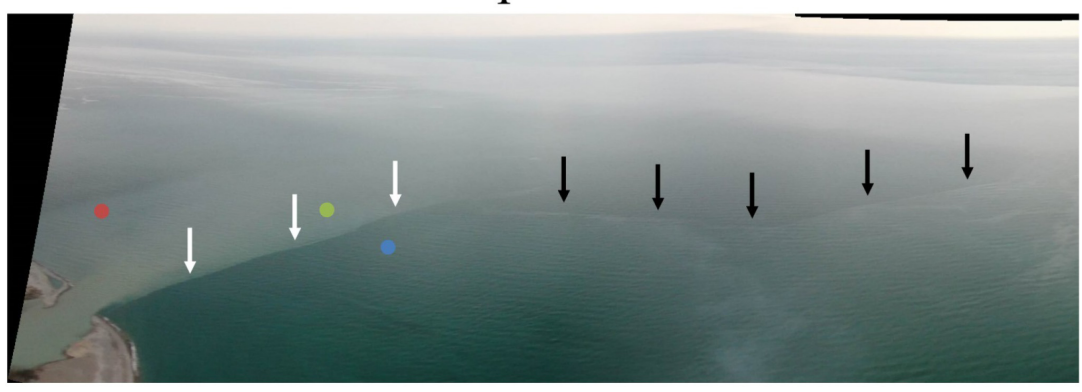

Salinity

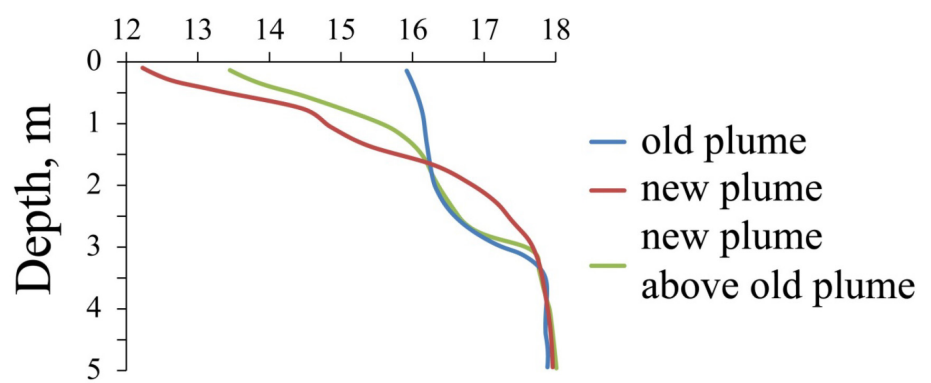

FIGURE 5 | Aerial panoramic image (A) and vertical salinity structure (B) of the near-field (new plume) and outer (old plume) parts of the Bzyb plume shortly after the plume reversal acquired on 16 April 2021 at 15:15. Colored dots in panel (A) indicate locations of vertical salinity measurements. White arrows indicate location of the border between the new plume and the old plume, black arrows indicate location of the border between the old plume and the ambient sea.

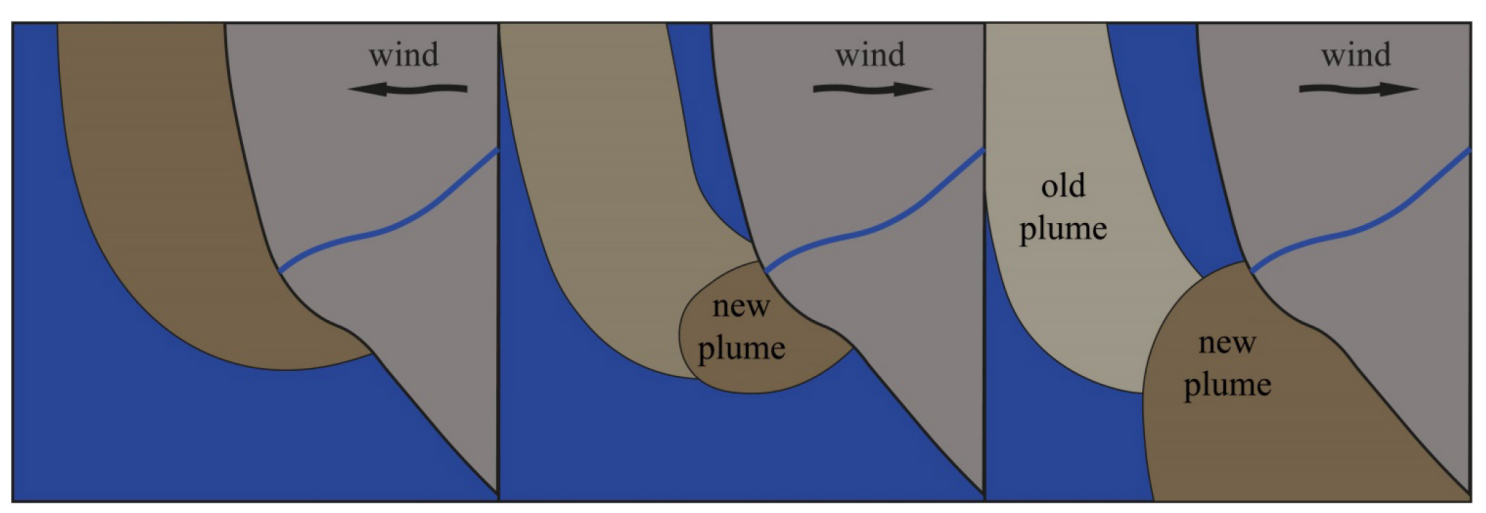

FIGURE 6 | The general scheme of the response of a small river plume to changes in upwelling/downwelling wind forcing. 
study area and have similar properties to the Bzyb plume (see Figure 5 in Osadchiev et al., 2020a). The relatively slow changes of the outer plume thickness and its onshore/offshore advection in response to downwelling/upwelling winds is consistent with previous numerical studies of large plumes (Fong and Geyer, 2001; Lentz, 2004; Lentz and Largier, 2006; Moffat and Lentz, 2012), albeit the near-field plume processes are significantly different for the small and large plumes. The general scheme of response of the new and old plumes to wind forcing described above is summarized in Figure 6.

$\mathrm{Qu}$ and Hetland (2019) reported that the accuracy of numerical simulation of an idealized river plume depends on temporal resolution of the applied wind forcing, namely, it is proportional to the fraction of energy missing in the highfrequency wind absent from the forcing. However, they analyzed variability of wind speed and did not consider variability of wind direction. In this study, we demonstrate the importance of resolving wind direction variability for simulation of a small river plume, which requires significantly smaller time step than that for resolving wind speed variability based on the energy spectrum. Once $10 \mathrm{~min}$ is the temporal scale of plume response to variability of wind forcing and $1 \mathrm{~h}$ is the temporal scale of plume reversal and reshaping, these time scales should be resolved in numerical modeling of a small river plume. Therefore, the time step of 3-4 h considered by Qu and Hetland (2019) as reasonable for simulation the effects of wind speed variability is not sufficient to resolve the effects of wind direction variability.

The linear dependence between wind speed and the Bzyb plume movement velocity was obtained only for low and moderate wind forcing conditions $(<6 \mathrm{~m} / \mathrm{s})$. Moreover, we considered only the fast changing wind. We presume that this linear relation would be distorted in case of durable onshore/offshore wind forcing. In this case, the plume is pressed to the shore and its outer border is stable, i.e., its advection velocity decreases to zero. In addition, the linear relation would be distorted in case of very strong wind, which induces intense mixing and dilution of the small river plume in ambient waters. The obtained relation could be different for different river plumes and, presumably, it depends on the vertical plume-sea salinity gradient, which is governed by river discharge rate. As a result,

\section{REFERENCES}

Berdeal, G. I., Hickey, B. M., and Kawase, M. (2002). Influence of wind stress and ambient flow on a high discharge river plume. J. Geophys. Res. 107:3130. doi: 10.1029/2001JC000932

Choi, B.-J., and Wilkin, J. L. (2007). The effect of wind on the dispersal of the Hudson River plume. J. Phys. Oceanogr. 37, 1878-1897. doi: 10.1175/JPO3081.1

Cole, K. L., MacDonald, D. G., Kakoulaki, G., and Hetland, R. D. (2020). River plume source-front connectivity. Ocean Model. 150:101571. doi: 10.1016/j. ocemod.2020.101571

Fong, D. A., and Geyer, W. R. (2001). Response of a river plume during an upwelling favorable wind event. J. Geophys. Res. 106, 1067-1084. doi: 10.1029/ 2000jc900134

Fong, D. A., and Geyer, W. R. (2002). The alongshore transport of freshwater in a surface-trapped river plume. J. Phys. Oceanogr. 32, 957-972. doi: 10.1175/152004852002032<0957:TATOFI<2.0.CO;2

Hallock, Z. R., and Marmorino, G. O. (2002). Observations of the response of a buoyant estuarine plume to upwelling favorable winds. J. Geophys. Res. 107:3066. doi: 10.1029/2000JC000698 it can vary among different seasons for the individual river plume in case of large synoptic or seasonal variability of river discharge. Second, the Bzyb River inflows to sea area with quasilinear shoreline and steep sea bottom slope, which is close to the idealized shoreline morphology and seafloor bathymetry. However, regional features of morphology and bathymetry can strongly modify the relation between wind speed and plume movement velocity. These issues require additional studies at different river plumes during different river discharge conditions. Usage of quadcopter to perform continuous aerial remote sensing of river plumes supported by synchronous in situ measurements holds promise to improve our understanding of spreading dynamics of river plumes worldwide.

\section{DATA AVAILABILITY STATEMENT}

The datasets presented in this study can be found in online repositories. The names of the repository/repositories and accession number(s) can be found below: https://doi.org/10. 5281/zenodo.5641881.

\section{AUTHOR CONTRIBUTIONS}

AO designed the study and wrote the first draft of the manuscript. $\mathrm{AO}, \mathrm{RS}$, and $\mathrm{AB}$ performed the field work and organized the database. AO and RS performed the analysis of the in situ and meteorological data. All authors contributed to manuscript revision, read, and approved the submitted version.

\section{FUNDING}

This research was funded by the Ministry of Science and Higher Education of the Russian Federation, theme 0128-2021-0001 (collecting of in situ data), the Russian Science Foundation, research project 18-17-00156 (study of river plumes), and the Russian Foundation for Basic Research, research project 19-5580004 (collecting and processing of aerial remote sensing data).

Horner-Devine, A. R. (2009). The bulge circulation in the Columbia River plume. Cont. Shelf Res. 29, 234-251. doi: 10.1016/j.csr.2007. 12.012

Horner-Devine, A. R., Fong, D. A., Monismith, S. G., and Maxworthy, T. (2006). Laboratory experiments simulating a coastal river inflow. J. Fluid Mech. 555, 203-232. doi: 10.1017/S0022112006008937

Horner-Devine, A. R., Hetland, R. D., and MacDonald, D. G. (2015). Mixing and transport in coastal river plumes. Annu. Rev. Fluid Mech. 47, 569-594. doi: 10.1146/annurev-fluid-010313-141408

Houghton, R. W., Tilburg, C. E., Garvine, R. W., and Fong, D. A. (2004). Delaware river plume response to a strong upwelling-favorable wind event. Geophys. Res. Lett. 31:L07302. doi: 10.1029/2003GL018988

Korshenko, E. A., Zhurbas, V. M., Osadchiev, A. A., and Belyakova, P. A. (2020). Fate of river-borne floating litter during the flooding event in the northeastern part of the Black Sea in October 2018. Mar. Pollut. Bull. 160:111678. doi: 10.1016/j.marpolbul.2020.111678

Lentz, S. J. (2004). The response of buoyant coastal plumes to upwellingfavorable winds. J. Phys. Oceanogr. 34, 2458-2469. doi: 10.1175/JPO 2647.1 
Lentz, S. J., and Fewings, M. R. (2012). The wind- and wave-driven inner-shelf circulation. Annu. Rev. Mar. Sci. 4, 317-343. doi: 10.1146/annurev-marine120709- 142745

Lentz, S. J., and Largier, J. (2006). The influence of wind forcing on the Chesapeake Bay buoyant coastal current. J. Phys. Oceanogr. 36, 1305-1316. doi: 10.1175/ JPO2909.1

Lihan, T., Saitoh, S. I., Iida, T., Hirawake, T., and Iida, K. (2008). Satellite-measured temporal and spatial variability of the Tokachi River plume. Estuar. Coast. Shelf Sci. 78, 237-249. doi: 10.1016/j.ecss.2007.12.001

Liu, Y., MacCready, P., Hickey, B. M., Dever, E. P., Kosro, P. M., and Banas, N. S. (2009). Evaluation of a coastal ocean circulation model for the Columbia River plume in summer 2004. J. Geophys. Res. 114:C00B04. doi: 10.1029/ 2008gl036447

Mazzini, P. L. F., and Chant, R. J. (2016). Two-dimensional circulation and mixing in the far field of a surface-advected river plume. J. Geophys. Res. 121, 3757-3776. doi: 10.1002/2015JC011059

Medvedev, I. P. (2018). Tides in the Black Sea: observations and numerical modeling. Pure Appl. Geophys. 175, 1951-1969. doi: 10.1007/s00024-0181878-x

Medvedev, I. P., Rabinovich, A. B., and Kulikov, E. A. (2016). Tides in three enclosed basins: the Baltic, Black, and Caspian seas. Front. Mar. Sci. 3:46. doi: $10.3389 /$ fmars. 2016.00046

Moffat, C., and Lentz, S. (2012). On the response of a buoyant plume to downwelling-favorable wind stress. J. Geophys. Res. 42, 1083-1098. doi: 10. 1175/JPO-D-11-015.1

Nehama, F. P. J., and Reason, C. J. C. (2021). Modelling the Zambezi River plume. Afr. J. Mar. Sci. 37, 593-604. doi: 10.2989/1814232X.2015.1113202

Nikiema, O., Devenon, J.-L., and Baklouti, M. (2007). Numerical modeling of the Amazon River plume. Cont. Shelf Res. 27, 873-899. doi: 10.1016/j.csr.2006. 12.004

Nof, D., and Pichevin, T. (2001). The ballooning of outflows. J. Geophys. Res. 31, 3045-3058. doi: 10.1175/1520-04852001031<3045:TBOO<2.0.CO;2

O'Callaghan, J., Rickard, G., Popinet, S., and Stevens, C. (2010). Response of buoyant plumes to transient discharges investigated using an adaptive solver. J. Geophys. Res. 115:C11025. doi: 10.1029/2009JC005645

Osadchiev, A. A. (2017). Spreading of the Amur river plume in the Amur Liman, the Sakhalin Gulf, and the Strait of Tartary. Oceanology 57, 376-382. doi: 10. 1134/S0001437017020151

Osadchiev, A. A. (2018). Small mountainous rivers generate high-frequency internal waves in coastal ocean. Sci. Rep. 8:16609. doi: 10.1038/s41598-01835070-7

Osadchiev, A. A., and Korshenko, E. A. (2017). Small river plumes off the northeastern coast of the Black Sea under average climatic and flooding discharge conditions. Ocean Sci. 13, 465-482. doi: 10.5194/os-13-465-2017

Osadchiev, A. A., and Sedakov, R. O. (2019). Spreading dynamics of small river plumes off the northeastern coast of the Black Sea observed by Landsat 8 and Sentinel-2. Remote Sens. Environ. 221, 522-533. doi: 10.1016/j.rse.2018.11.043

Osadchiev, A. A., and Zavialov, P. O. (2013). Lagrangian model of a surfaceadvected river plume. Cont. Shelf Res. 58, 96-106. doi: 10.1016/j.csr.2013.03.010

Osadchiev, A. A., and Zavialov, P. O. (2020). "Structure and dynamics of plumes generated by small rivers," in Estuaries and Coastal Zones - Dynamics and Response to Environmental Changes, ed. J. Pan (London: IntechOpen).

Osadchiev, A. A., Asadulin, E. E., Miroshnikov, A. Y., Zavialov, I. B., Dubinina, E. O., and Belyakova, P. A. (2019). Bottom sediments reveal inter-annual variability of interaction between the $\mathrm{Ob}$ and Yenisei plumes in the Kara Sea. Sci. Rep. 9:18642. doi: 10.1038/s41598-019-55242-3

Osadchiev, A. A., Barymova, A. A., Sedakov, R. O., Zhiba, R. Y., and Dbar, R. S. (2020a). Spatial structure, short-temporal variability, and dynamical features of small river plumes as observed by aerial drones: case study of the Kodor and Bzyp river plumes. Remote Sens. 12:3079. doi: 10.3390/rs12183079

Osadchiev, A. A., Pisareva, M. N., Spivak, E. A., Shchuka, S. A., and Semiletov, I. P. (2020b). Freshwater transport between the Kara, Laptev, and East-Siberian seas. Sci. Rep. 10:13041. doi: 10.1038/s41598-020-70096-w

Osadchiev, A. A., Barymova, A. A., Sedakov, R. O., Rybin, A. V., Tanurkov, A. G., Krylov, A. A., et al. (2021a). Hydrophysical structure and current dynamics of the Kodor river plume. Oceanology 61, 1-14. doi: 10.1134/S000143702101015X

Osadchiev, A. A., Sedakov, R. O., Barymova, A. A., and Gordey, A. S. (2021b). Internal waves as a source of concentric rings within small river plumes. Remote Sens. 13:4275. doi: 10.3390/rs13214275
Osadchiev, A. A., Silvestrova, K. P., and Myslenkov, S. A. (2020c). Wind-driven coastal upwelling near large river deltas in the Laptev and East-Siberian seas. Remote Sens. 12:844. doi: 10.3390/rs12050844

Perianez, R. (2005). Modelling the dispersion of radionuclides by a river plume: application to the Rhone river. Cont. Shelf Res. 25, 1583-1603. doi: 10.1016/j. csr.2005.04.001

Pinones, A., Valle-Levinson, A., Narvaez, D. A., Vargas, C. A., Navarrete, S. A., Yuras, G., et al. (2005). Wind-induced diurnal variability in river plume motion. Estuar. Coast. Shelf Sci. 65, 513-525. doi: 10.1016/j.ecss.2005.06.016

Qu, L., and Hetland, R. D. (2019). Temporal resolution of wind forcing required for river plume simulations. J. Geophys. Res. 124, 1459-1473. doi: 10.1029/ 2018jc014593

Rao, S., Pringle, J., and Austin, J. (2011). Upwelling relaxation and estuarine plumes. J. Geophys. Res. 116, C09023. doi: 10.1029/2010JC006739

Saldias, G. S., Sobarzo, M., Largier, J., Moffat, C., and Letelier, R. (2012). Seasonal variability of turbid river plumes off central Chile based on high-resolution MODIS imagery. Remote Sens. Environ. 123, 220-233. doi: 10.1016/j.rse.2012. 03.010

Shi, W., and Wang, M. (2010). Satellite observations of the seasonal sediment plume in central East China Sea. J. Mar. Syst. 82, 280-285. doi: 10.1016/j. jmarsys.2010.06.002

Thomas, A., and Weatherbee, R. A. (2006). Satellite-measured temporal variability of the Columbia River plume. Remote Sens. Environ. 100, 167-178. doi: 10.1016/ j.rse.2005.10.018

Whitney, M. M., and Garvine, R. W. (2005). Wind influence on a coastal buoyant outflow. J. Geophys. Res. 110:C03014. doi: 10.1029/2003jc002261

Williams, W. J., Weingartner, T. J., and Hermann, A. J. (2010). Idealized twodimensional modeling of a coastal buoyancy front, or river plume, under downwelling-favorable wind forcing with application to the Alaska Coastal Current. J. Geophys. Res. 40, 279-294. doi: 10.1175/2009jpo4206.1

Xia, M., Xie, L., Pietrafesa, L. J., and Whitney, M. M. (2011). The ideal response of a Gulf of Mexico estuary plume to wind forcing: its connection with salt flux and a Lagrangian view. J. Geophys. Res. 116:C08035. doi: 10.1029/2010JC 006689

Yankovsky, A. E., and Chapman, D. C. (1997). A simple theory for the fate of buoyant coastal discharges. J. Geophys. Res. 27, 1386-1401. doi: 10.1175/152004851997027<1386:ASTFTF<2.0.CO;2

Yankovsky, A. E., Hickey, B. M., and Münchow, A. K. (2001). Impact of variable inflow on the dynamics of a coastal buoyant plume. J. Geophys. Res. 106, 19809-19824. doi: 10.1029/2001jc000792

Yuan, Y., Horner-Devine, A. R., Avener, M., and Bevan, S. (2018) The role of periodically varying discharge on river plume structure and transport. Cont. Shelf Res. 158, 15-25. doi: 10.1016/j.csr.2018. 02.009

Zhao, J., Gong, W., and Shen, J. (2018). The effect of wind on the dispersal of a tropical small river plume. Front. Earth Sci. 12:170-190. doi: 10.1007/s11707016-0628-6

Zu, T., Wang, D., Gan, J., and Guan, W. (2014). On the role of wind and tide in generating variability of Pearl River plume during summer in a coupled wide estuary and shelf system. J. Mar. Syst. 136, 65-79. doi: 10.1016/j.jmarsys.2014. 03.005

Conflict of Interest: The authors declare that the research was conducted in the absence of any commercial or financial relationships that could be construed as a potential conflict of interest.

Publisher's Note: All claims expressed in this article are solely those of the authors and do not necessarily represent those of their affiliated organizations, or those of the publisher, the editors and the reviewers. Any product that may be evaluated in this article, or claim that may be made by its manufacturer, is not guaranteed or endorsed by the publisher.

Copyright (c) 2021 Osadchiev, Sedakov and Barymova. This is an open-access article distributed under the terms of the Creative Commons Attribution License (CC BY). The use, distribution or reproduction in other forums is permitted, provided the original author(s) and the copyright owner(s) are credited and that the original publication in this journal is cited, in accordance with accepted academic practice. No use, distribution or reproduction is permitted which does not comply with these terms. 